\title{
The effects of student's gender and classroom disruptive behaviors and parental income on student's mathematics achievement trajectory
}

\author{
Fatih Koca \\ Trabzon University, Fatih College of Education, Turkey (ORCID: 0000-0002-3754-7283)
}

\begin{abstract}
The goal of the study was to examine the role of students' gender, their disruptive behaviors, and parental income on their mathematics achievement history. Participants included 8,984 individuals aged 12-16 years and the data were collected from the National Longitudinal Surveys (NLS). The study results showed that there was not any significant gender effect on students' mathematics achievement trajectories. Furthermore, students with disruptive behaviors were more successful than their peers with less disruptive behaviors. Finally, the latent growth curve model parameter estimates indicated there was not any significant parental earned income impact on students' mathematics achievement trajectories.
\end{abstract}

Keywords: Parental - income; Mathematics achievement; Gender

Article History: Submitted 21 April 2021; Revised 27 January 2022; Published online 22 February 2022

\section{Introduction}

A growing body of research has indicated that unfortunately, research and statistics provide evidence supporting the existence of a gender gap in mathematics (e.g., Catsambis, 1994; Evens et al., 1997). Problem solving and mathematical skills are crucial for future generations' successes. It is well documented that girls are underrepresented in college majors, advanced degree programs and careers related to mathematics (Beilock et al., 2009; Catsambis, 1994; Fennema \& Shearmen, 1977; Nosek et al., 2009). Furthermore, resent studies in mathematical achievement are driven by the importance in both formal education and individuals' daily lives (Jansen et al., 2013; Namkung et al., 2019). Jain and Dowson (2009) pointed out that mathematical comprehension is significant for personal and Professional success. In fact, math achievement is linked to various demographic factors (e.g., health, income, gender) and psychological factors including well-being, life satisfaction and resiliency.

Although females tend to be better than their counterpart males in mathematics classes, they continue to score lower on tests including the SATs (Catsambis, 1994). Catsambis (1994) defined the term 'Numeracy Gender Gap' as the discrepancies in attitude, skills, and mathematical behaviors between males and females. Furthermore, in the beginning of the 1980s, standardized test scores showed that girls were significantly behind in math. For example, Catsambis (1994)

Address of Corresponding Author

Fatih Koca, PhD, Fatih College of Education, Trabzon University, C Block Room 105, Trabzon, Turkey.

$\triangle$ fkoca@trabzon.edu.tr

How to cite: Koca, F. (2022). The effects of student's gender and classroom disruptive behaviors and parental income on student's mathematics achievement trajectory. Journal of Pedagogical Research, 6(1), 67-86. https:// dx.doi.org/10.33902/JPR.2022175516 
pointed out that results from national assessment tests showed 17-year-old boys lead girls by only five points in math. Furthermore, Nosek et al. (2009) examined the role of national-level implicit stereotypes regarding sex differences in science and math achievement. They found that implicit stereotypes and sex differences in science and math participation were statistically significant predictor of students' performance in $8^{\text {th }}$ grade classroom settings. Similarly, Beilock et al. (2009) investigated how female teachers' math anxiety play a role in girls' math achievement. They showed that female teacher' stereotypic beliefs and math anxiety were statistical predictors of girls' mathematics achievement. In other words, female students tend to have less positive math attitudes. In fact, they might develop lower leves math self-efficacy beliefs in their math skills as compared to male students. For instance, even if female students exhibit similar or better performance levels to male ones, they often feel less efficious of themselves. Especially, we specifically observe the gender differences in spatial skills, math-intensive career choices, and college entrance. Theoratically, research has showed the importance of self-concept in encouraging female to pursue in a career path and college degree in mathematics (Niepel et al., 2019). However, gender differences in both mathematics attitudes (i.e., math self-concept) and content knowledge might result in gender inequality in future math-related career choices. For example, Goldman and Penner (2014) found that a reason female student is under-represented in the academic disciplines of science, techonolog, and mathematics fields. In fact, several studies also pointed out that the increasing gender gap in math self-concept might later generate stereotypic and actual gender differences in STEM field (e.g., Cvencek et al., 2011; Rubie-Davies \& Lee, 2013).

Research has also indicated that the increasing gender gap in math self-concept might later lead to actual gender differences in mathematics achievement (Casey et al., 2001; Cvencek et al., 2011). Existing research has found no significant gender differences in the global assessment of selfconcept between males and females (Rubie-Davies \& Lee, 2013), but has found significant gender differences in specific domains of self-concept, specifically in self-concept for mathematical problem-solving, where males reported higher math selfconcept than females (Casey et al., 2001; Good et al., 2012; Kung \& Lee, 2016), and beliefs of math selfefficacy and fear of failure, where boys favored larger for self-beliefs than girls (Louis \& Mistele, 2012; Ross et al., 2012). These results are consistent with those of Cvencek et al. (2011), who indicated that adolescent girls had a lower math self-concept than boys, consistent with gender stereotypes. In addition, Ozogul and Sullivan (2009) examined students' self-concept, and the results indicated that females had lower math selfconcept, whereas males had lower self-concept for academics and language. By contrast, Nagy et al. (2010) examined gender differences in math self-concept and reported that gender was not significantly related to self-concept. Nagy et al. (2010) concluded that gender-related differences in math self-concept should be questioned. While results seemed to contradict past research implicating gender stereotypes, the studies used indefinite constructs in measuring self-concept, which limited the possibility of an individual obtaining different results across self-concept domains.

The relationship between cognitive, motivational, and affective variables and mathematics achievement might critically influenced by students'gender, behavioral problems, and parental income. Achievement in mathematics seems to vary depending on students' gender. In addition, although some researchers have found that the gender gap in mathematics has been in favor of male studens (Williams et al., 2016), others have pointed out that male and female students have exhibited no differences in mathematical achievement, especially in countries with equal education for both gender (Spelke, 2005). As far as our knowledge, there are not enough data about gender achievement gap regarding longitudianal research.

Additionally, the mathematics achievement levels of U.S. students fall far behind those of other developed nations; within the United States itself, the students who are falling behind come predominantly from high-poverty (Blank \& Langesen, 1999; Blums et al., 2016). In fact, unfortunately poor students in American educational system have been receiving weak academic preparations in their middle school years; and therefore the achievement gap between low and 
high SES students is increasing (Blank \& Langesen, 1999). Accordingly, Blums et al. (2016) employed a structural equation model to examine direct and indirect role of socioeconomic status in students' achievement in science, technology, engineering, and math (STEM) education. They found that the indicators of SES including maternal education and parental income directly and indirectly affected the students' verbal, basic calculation, and reasoning skills. Plausible causes of the gap, based on previous studies, are unfocused curricula and shortages of skilled, trained, and knowledgeable mathematics teachers (Blank \& Langesen, 1999; Burill, 1998). Although all these factors are related to school-based causes, Blank and Langesen stressed on the significance of poverty on students' mathematics achievement.

Students with internalizing and externalizing behavioral problems often demonstrate challenging behaviours and have difficulties in remaining focused on the lesson, learning less than their peers, resulting in lower academic success and dropping out of school. Behavioral problems are indicators of several ubiquitous mental health problems that often emerge during early adolescent times, including conduct disorders, mood disorders, and substance use disorders (Merikangas et al., 2009). Also, academic achievement might be critical indicator of mental health problems (Suldo et al., 2011) and declines in school success might be serious as children enter elementary school (Blackwell et al., 2007). Therefore, the students' disruptive behaviors have detrimental effects on student academic achievement (Campbell, 1994; Mendoza et al., 2013; Pianta, 1999, 2001; Birch \& Ladd, 1998). Accordingly, Pianta (1999) found that students with externalizing behavioral problems (e.g., aggression and classroom disruption) were at risk of academic failure and school dropout. Mendoza et al. (2013) conducted a study to examine the predictive role of psychoticism and disruptive behavior on school achievement. Classroom disruptive behaviors and psychoticism carried statistically significant role in school performance. Similarly, DiPrete and Jennings (2012) examined social/behavioral skills and gender gap in early educational achievement. They demonstrated that social and behavioral orientations (i.e., internalizing and externalizing behavioral problems) had a crucial resource for academic achievement in primary and elementary classroom settings.

Together, youth's and adolescents' behavioral functioning is key to their owerall academic achievement and socio-emotional development. The current study focuses on students' disruptive behaviours that lead to impair their academic development in mathematics from elementary to high school years over time. These problematic behaviours distract the students and interfere with their ability to engage in their mathematics learning. Unfortunately, they might also influence a teacher's perception of a student's math achievement (Zimmermann et al., 2013). Therefore,understanding and documenting the impact of student's gender, their disruptive behaviors, and parental income on students' mathematics achievement trajectory are needed.

\section{Method}

\subsection{Participants}

Participants included 8,984 individuals aged 12-16 years and the data were collected from the National Longitudinal Surveys (NLS). This longitudinal survey was sponsored by the Bureau of Labor Statistics and the surveys "are a family of surveys dedicated to tracking the labor market and other life experiences of American men and women" (NLS, April 15, https:/ / www.nlsinfo.org). The data were collected in 1979-1997 and consists of seven NLS cohorts. They are (1) National Longitudinal Survey of Youth 1997 (NLSY97), (2) National Longitudinal Survey of Youth 1979 (NLSY79), (3) NLSY79 Child and Young Adult, (4) Older Men, (5) Mature Women, (6) Young Men and (7) Young Women. Participation in the national evaluation was voluntary.

- Gender: 4,599 males (51.2\%) and 4,385 females (48.8\%), so there was not any missing. In our data file, male and female were coded as 0 and 1 respectively.

- Race: 2,335 African-American (26 \%), 1,901 Hispanic (21.2 \%), 4,665 Non-Black and Hispanic $(51.9 \%)$, and 83 Mixed (0.9 \%). There was not any missing on the data file. In our data file, we 
coded race as follow: 1=African-American, 2=Hispanic, 3= Mixed, and 4=Non-Black and Hispanic.

- Age: 1,771 aged 12 (19.7\%), 1,807 aged 13 (20.1\%), 1,841 aged 14 (20.5\%), 1,874 aged 15 $(20.9 \%), 1,691$ aged $16(18.8 \%)$, and mean age for all participants is 13.99 (SD=1.39).

\subsection{Sample Size, Power, and Precision}

The intended sample size was $N=8,984$. There were not any criteria to determine the sample size and therefore all participants' data will be used in this study. The sample size of $>4,000$ has sufficient power for structural equation modeling (Byrne, 2012). Accordingly, latent growth modeling is a statistical technique used in the structural equation modeling framework to estimate growth trajectory (Byrne, 2012).

\subsection{Measure and Study Variables}

All participants who participated in the national evaluation were given a standardized battery of measures. NSLY97 questionnaires record (1) interview dates; (2) responses to the topical survey questions; (3) locating information which will help in finding the respondent for the next interview; and (4) interview remarks on such topics as the race and gender of the respondent, language in which the interview was conducted, the interview's impression, etc (see the Data Manual (NLSY, 1997) for the complete list of measures given to participants). Data were collected using self-reports and through structured interviews with trained interviewers. The reliability and validity of the study were addressed in the Investigator Guide by National Longitudinal Survey at the U.S. Bureau of Labor Statistics (1922).

\subsubsection{Mathematics PIAT Scores}

The NLSY97 collects information from a variety of standardized achievement tests commonly taken by young adults in junior high school and high school; these data are described in the "Achievement Tests" subsection. NLSY97 respondents take the Peabody Individual Achievement Test (Markwardt \&Frederick, 1998; PIAT) Math Assessment as a part of the interview. The Peabody Individual Achievement Test (PIAT) measures academic achievement of children ages five and over. It is among the most widely used brief assessments of academic achievement, with demonstrably high test-retest reliability and concurrent validity. One of the PIAT subtests, the Mathematics Assessment, was given to round 1 respondents not yet enrolled in the 10th grade. In rounds 2 through 5, this test was given to respondents who were age 12 as of December 31, 1997, and who were in the 9th grade or lower in round 1. By comparing the test score on the PIAT Math Assessment with information on the respondent's math courses from the Youth Questionnaire and the transcript survey, researchers may be able to assess correlations between curriculum and math performance. This PIAT Math achievement scores in 1997 (R12118); 1998 (R25697); 1999 (R38917); 2000 (R54737); 2001 (R72374); and 2002 (S15527) will be used as outcome variable.

\subsubsection{Gender and Student Disruptions}

Student's gender (R05363) and behavioral disruptions (YSCH3660) will be used as time-invariant covariant variables in this study. In the self-administrated section of the Youth Questionnaire, a computer-assisted self-interview, collects sensitive data that reflect anti-social behavior (e.g., substance use, delinquency, behavioral problems), as well as detailed attitudes about schooling, sexual activity, and dating. The round 1 NLSY97 survey attempted to ascertain the impact that school has had on the feelings of well-being experienced by various youths. To this end, respondents who were enrolled at the time of the survey were asked to agree or disagree with the following statements regarding their school's environment and their teachers. For example, student disruptions was measured as: "Students disrupt learning agree $\backslash$ disagree. Disruptions by other students get in the way of my learning". Students rated this specific question by 4-Likert type scale (1-Strongly Agree to 4-Strongly Disagree) (Achenbach, 1991). 


\subsubsection{Parental Income}

Total earned income was used as time-variant covariant variable in this study. Total earned income includes wages, salary, self-employment, interest, food stamps, supplemental security, child support, and all other income. The total earned income was collected six times:

- Income 1997 (R12045); Income 1998 (R25633); Income 1999 (R38849); Income 2000 (R54461); Income 2001 (R72278); and Income 2002 (S15417).

\subsection{Research Design and Data Analyses}

The data in this study were subjected to statistical assumption testing and the latent growth modeling. SPSS (version 20) was used to analyze the data for normality, outliers, and to ensure against non-normality. It was also used to conduct a univeriate latent growth curve modeling to determine the impacts of time-invariant and time-variant covariates on students' mathematics achievement trajectories. MPlus (version 7) was used to conduct the latent growth modeling.

Using latent-growth modeling, the study tried to analyze and estimate the effects of an earned income time-variant covariate on growth in the participants' math achievement trajectories over a period of time (between 1997 and 2002). Through this analysis, the study would like to examine the effects of students' gender and behavioral disruptions on their growth math achievement trajectories on six time points.

\section{Results}

\subsection{Data Screening}

\subsubsection{Assumptions and data preparation}

The researcher checked for mis-entered data by running a frequency check on all the variables that were to be used in the model. Review of the frequency check indicated no mis-entered / inappropriately entered data. All data points for all participants were accounted for and within the possible ranges of response. Therefore, the researcher has deleted these cases. In addition, all missing values were identified and coded as "99999".

The researcher also checked for the assumption of univeriate normality by running explores and frequencies analyses on the study variables. The outcome variable (PIAT scores) and the timevariant covariate variable (Parent Income) were frequently found to be in violation of this normality assumption. In many instances, there were twenty-three cases that acted as outliers in several time points.

\subsection{The Latent Growth Curve Model}

For the purpose of the study, the study concentrated on participants' PIAT scores as mathematics achievement measured at years 1997, 1998, 1999, 2000, 2001, and 2002. In addition to mathematics achievement scores, we also include gender (female $=1$ and male $=0$ ) and student disruptive behavior (SDB) as time-invariant covariate variable. Time varying predictor included parental income in order to see the effects of economical power on students' mathematics achievement trajectories.

\subsubsection{Sample statistics}

As presented in Table 1, the estimated sample statistics for these data were computed. Turning first to the means of the outcome and time-variant covariate variables, it is clear that there are minimal fluctuations across the years between 1997 and 2000 for both PIAT mathematics achievement scores and parental income (time-variant covariate). In fact, there appears to be virtually non-linear relationship and no difference in mathematic scores. Therefore, these mean scores suggest that evidence of change in slope related to construct across a 6-time points will likely to be minimal. 
The researcher also computed the variances on the main diagonal of the covariance matrix; mathematics achievement scores collected in 1998 and 1999 exhibited the most variability across students. That a wide fluctuation of individual trajectories occurred at 1998 and 1999 seems to suggest that the students might be familiar with the content of the achievement test.

Table 1

Descriptive Data for Estimated Sample Statistics

\begin{tabular}{lcc|}
\hline & Mean & SD \\
\hline PIAT97 & 96.55 & 19.54 \\
PIAT98 & 97.07 & 18.93 \\
PIAT99 & 96.31 & 18.75 \\
PIAT00 & 96.00 & 16.72 \\
PIAT01 & 97.14 & 17.78 \\
PIAT02 & 94.47 & 17.53 \\
INCOME97 & 681 & 1314 \\
INCOME98 & 1512 & 2420 \\
INCOME99 & 2985 & 4577 \\
INCOME00 & 4814 & 5872 \\
INCOME01 & 6801 & 7284 \\
INCOME02 & 9027 & 8723 \\
\hline
\end{tabular}

\subsection{Growth in Mathematics Achievement (No Covariates)}

Table 2 presents the results of the linear growth curve modeling without any covariates and predictors. A path diagram of this model is shown in Figure 1. This model was estimated allowing eroscedastic but non-autocorrelated disturbances. In addition, fit model without covariates, fixed time scores were used to test if the latent growth model was linear.

Figure 1

Growth in Mathematics Achievement (No Covariates)

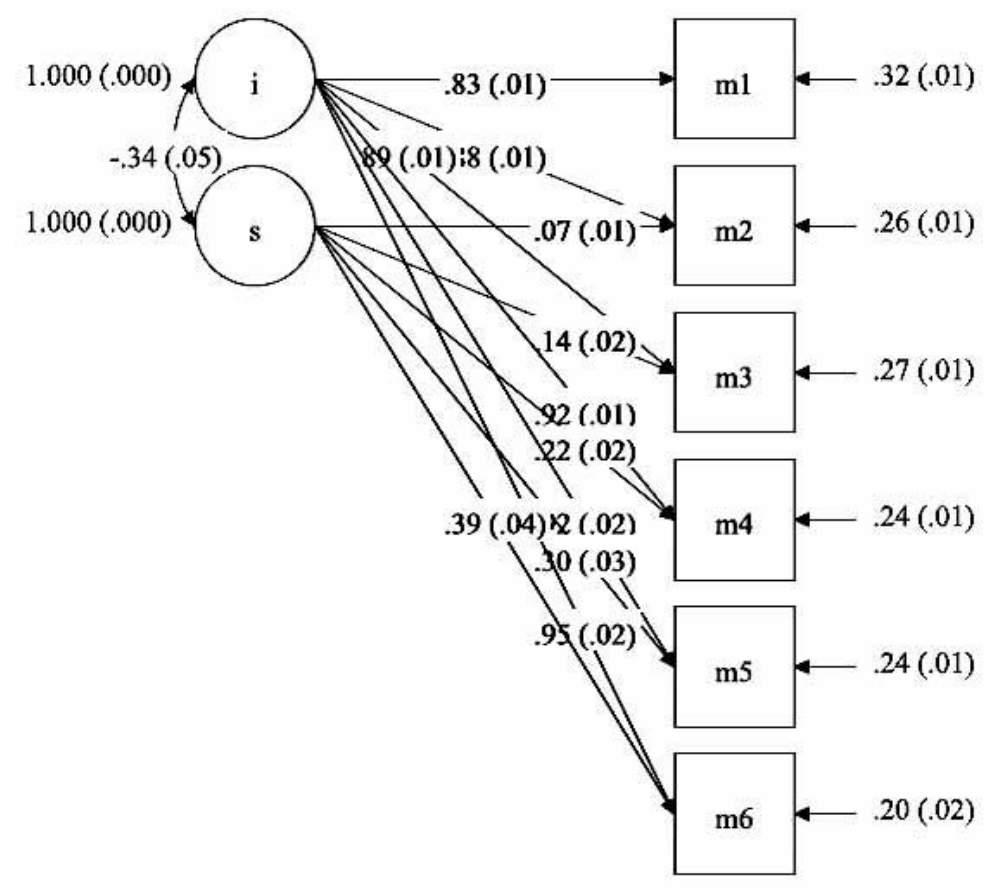


Table 2

Selected Results of Growth Curve Model of Mathematics Achievement

\begin{tabular}{ccccccccc}
\hline & \multicolumn{3}{c}{ Standardized Estimates } & \multicolumn{3}{c}{ Unstandardized Estimates } \\
\cline { 2 - 8 } & Est. & SE & Z & Sig & Est. & SE & Z & Sig \\
\hline I (Intercept) I & & & & & & & & \\
PIAT97 & 0.83 & 0.08 & 105.50 & 0.00 & 1.00 & 0.00 & 999.00 & 999.00 \\
PIAT98 & 0.88 & 0.01 & 87.46 & 0.00 & 1.00 & 0.00 & 999.00 & 999.00 \\
PIAT99 & 0.89 & 0.01 & 71.07 & 0.00 & 1.00 & 0.00 & 999.00 & 999.00 \\
PIAT00 & 0.92 & 0.01 & 59.42 & 0.00 & 1.00 & 0.00 & 999.00 & 999.00 \\
PIAT01 & 0.92 & 0.02 & 96.78 & 0.00 & 1.00 & 0.00 & 999.00 & 999.00 \\
PIAT02 & 0.94 & 0.02 & 45.76 & 0.00 & 1.00 & 0.00 & 999.00 & 999.00 \\
S (Slope) I & & & & & & & & \\
PIAT97 & 0.00 & 0.00 & 999.00 & 999.00 & 1.00 & 0.00 & 999.00 & 999.00 \\
PIAT98 & 0.07 & 0.01 & 8.99 & 0.00 & 1.00 & 0.00 & 999.00 & 999.00 \\
PIAT99 & 0.15 & 0.02 & 8.99 & 0.00 & 1.00 & 0.00 & 999.00 & 999.00 \\
PIAT00 & 0.23 & 0.03 & 8.95 & 0.00 & 1.00 & 0.00 & 999.00 & 999.00 \\
PIAT01 & 0.30 & 0.04 & 8.91 & 0.00 & 1.00 & 0.00 & 999.00 & 999.00 \\
PIAT02 & 0.39 & 0.04 & 9.03 & 0.00 & 1.00 & 0.00 & 999.00 & 999.00 \\
S with I & & & & & & & & \\
Variances & -0.34 & 0.05 & -6.46 & 0.00 & -7.19 & 1.49 & -4.81 & 0.00 \\
I & 1.00 & 0.00 & 999.00 & 999.00 & 263.37 & 7.71 & 34.17 & 0.00 \\
S & 1.00 & 0.00 & 999.00 & 999.00 & 1.75 & 0.39 & 4.16 & 0.00 \\
\hline
\end{tabular}

The result indicated that the average mathematics achievement score is 263.37 and increases at an average of 7.71 points a year. The correlation between the initial status and rate of change was negative suggesting the possibility of ceiling effect. Furthermore, this fixed latent growth model showed that there was a rapid change and therefore, the researcher also freely estimated our model without covariant variables.

Table 3 presents the results of the linear growth modeling of mathematics achievement. The researcher selected the MLR estimator as it can correct the maximum likelihood (ML) chi-square statistic to take the missingness of the data. Here the researcher found a corrected $\chi^{2}$ value of 130.265 with sixteen degrees of freedom; the significance value was reported as $p<0.0001$. The researcher found values of $0.034(\mathrm{CI}=0.029-0.040)$ for RMSE and 0.982 and 0.983 for CFI/TFI respectively. The values and estimations based on the fit indexes are acceptable.

Table 3

Selected Goodness-of-fit Statistics

\begin{tabular}{|c|c|c|c|c|}
\hline Test of Model Fit & $\begin{array}{l}\text { Chi-Square Test of Model } \\
\text { Fit }\end{array}$ & CFI/TLI & RMSEA & SRMR \\
\hline Value & 130.265 & $0.982 / 0.983$ & 0.034 & 0.095 \\
\hline Degrees of Freedom & 16 & & & \\
\hline$p$-Value & 0.0000 & & & \\
\hline $\begin{array}{l}90 \text { percent confidence } \\
\text { interval }(\mathrm{CI})\end{array}$ & & & $0,029 / 0.040$ & \\
\hline Probability RMSEA $<=.05$ & & & 1.000 & \\
\hline
\end{tabular}

Table 4 and 5 present the results of the non-linear growth curve modeling without any covariates and predictors. A path diagram of this model is shown in Figure 2. This model was estimated allowing eroscedastic but non-autocorrelated disturbances. In addition, fit model without covariates freed time scores were used to test the mathematics achievement trajectories. 
Table 4

Selected Results of Growth Curve Model of Mathematics Achievement

\begin{tabular}{ccccccccc}
\hline & \multicolumn{3}{c}{ Standardized Estimates } & \multicolumn{3}{c}{ Unstandardized Estimates } \\
\cline { 2 - 9 } & Est. & SE & Z & Sig & Est. & SE & Z & Sig \\
\hline I (Intercept) I & & & & & & & & \\
PIAT97 & 0.82 & 0.08 & 108.14 & 0.00 & 1.00 & 0.00 & 999.00 & 999.00 \\
PIAT98 & 0.88 & 0.01 & 136.34 & 0.00 & 1.00 & 0.00 & 999.00 & 999.00 \\
PIAT99 & 0.89 & 0.01 & 120.59 & 0.00 & 1.00 & 0.00 & 999.00 & 999.00 \\
PIAT00 & 0.98 & 0.02 & 59.50 & 0.00 & 1.00 & 0.00 & 999.00 & 999.00 \\
PIAT01 & 0.92 & 0.02 & 81.83 & 0.00 & 1.00 & 0.00 & 999.00 & 999.00 \\
PIAT02 & 0.95 & 0.01 & 68.09 & 0.00 & 1.00 & 0.00 & 999.00 & 999.00 \\
S (Slope) I & & & & & & & & \\
PIAT97 & 0.00 & 0.00 & 999.00 & 999.00 & 1.00 & 0.00 & 999.00 & 999.00 \\
PIAT98 & 0.03 & 0.02 & 13.77 & 0.00 & 0.47 & 0.00 & 999.00 & 999.00 \\
PIAT99 & 0.09 & 0.02 & 13.84 & 0.00 & 1.61 & 0.00 & 999.00 & 999.00 \\
PIAT00 & 0.42 & 0.03 & 13.39 & 0.00 & 6.72 & 0.00 & 999.00 & 999.00 \\
PIAT01 & 0.26 & 0.02 & 13.82 & 0.00 & 4.35 & 0.00 & 999.00 & 999.00 \\
PIAT02 & 0.27 & 0.02 & 13.71 & 0.00 & 4.34 & 0.00 & 999.00 & 999.00 \\
S with I & & & & & & & & \\
& -0.40 & 0.04 & -10.46 & 0.00 & -6.73 & 0.84 & -8.02 & 0.00 \\
\hline
\end{tabular}

The result indicated that the average mathematics achievement score is 265.14 and increases an average of 1.096 points a year. The correlation between the initial status and rate of change was negative suggesting the possibility of ceiling effect. Table 6 details the goodness-of-fit indexes. Here the researcher found a corrected $\chi^{2}$ value of 77.419 with sixteen degrees of freedom; the significance value is reported as $p<0.0001$. The researcher found values of 0.025 (CI=0.020-0.031) for RMSE and 0.990 and 0.991 for CFI/TFI respectively. The values and estimations based on the fit indexes shows that there is a perfect fit in the model.

Figure 2

Growth in Mathematics Achievement (No covariate and freed)

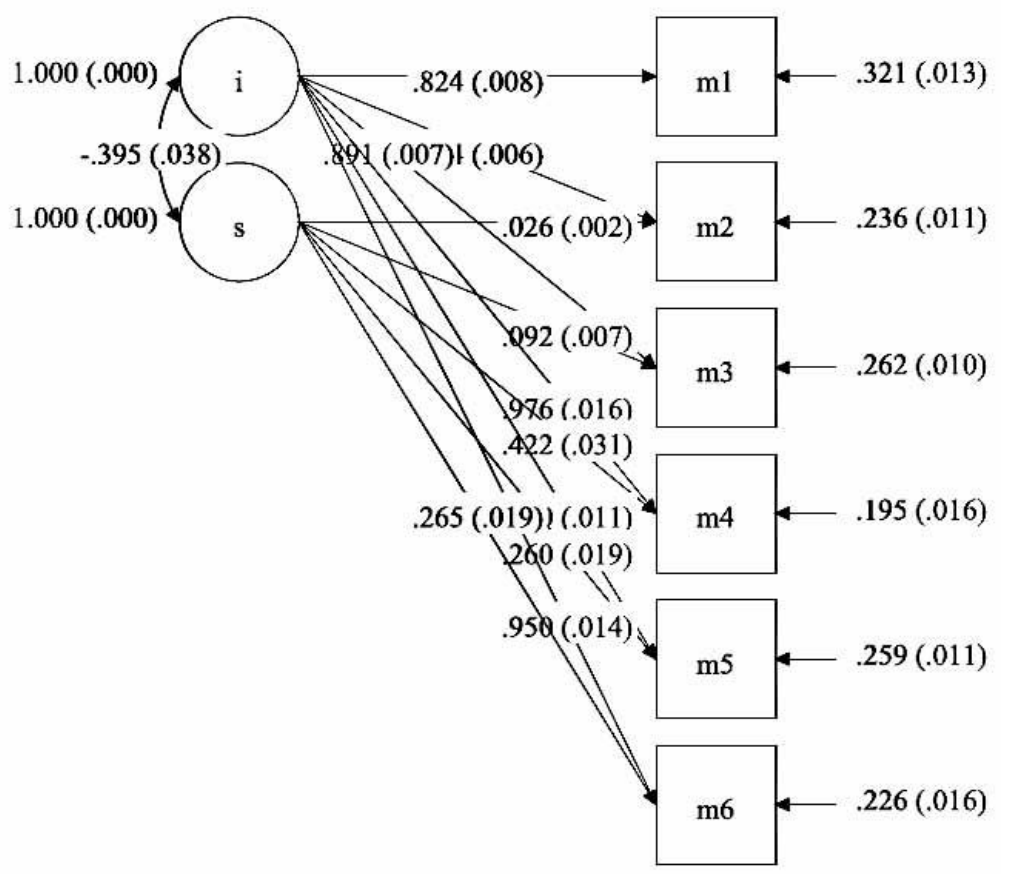


Table 5

Selected Goodness-of-fit Statistics for non-linear latent growth curve modeling

\begin{tabular}{|c|c|c|c|c|}
\hline Test of Model Fit & $\begin{array}{l}\text { Chi-Square Test of Model } \\
\text { Fit }\end{array}$ & CFI/TLI & RMSEA & SRMR \\
\hline Value & 77.419 & $0.990 / 0.991$ & 0.025 & 0.092 \\
\hline Degrees of Freedom & 16 & & & \\
\hline$p$-Value & 0.0000 & & & \\
\hline $\begin{array}{l}90 \text { percent confidence } \\
\text { interval }(\mathrm{CI})\end{array}$ & & & $0,020 / 0.031$ & \\
\hline Probability RMSEA<=.05 & & & 1.000 & \\
\hline
\end{tabular}

\subsection{Growth Curve Model of Mathematics Achievement with Time-Invariant Covariate Variables (Gender and Student Disruptive Problems)}

Table 6 and 7 present the results of the linear growth curve model with gender and student disruptive problems as time-invariant predictors of initial status and growth rate. A path diagram of this model is shown in Figure 3. The results indicated that there was not a significant difference between female and male students in mathematics achievement trajectories.

Figure 3

Linear Growth Curve Model of Mathematics Achievement with Time-Invariant Predictors

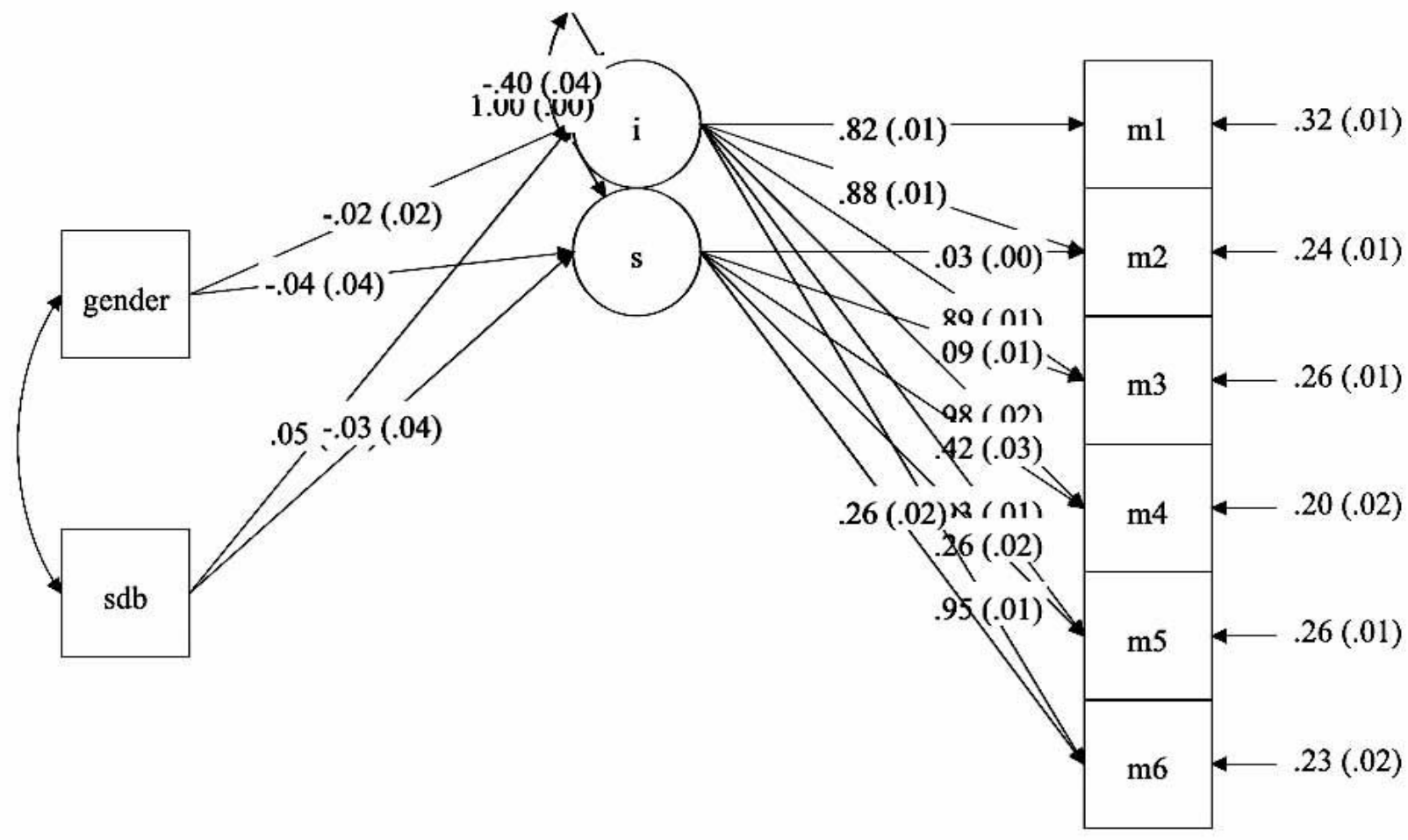

The result indicated that the average mathematics achievement score is 94.18 and decreases an average of 0.126 points a year. The correlation between the initial status and rate of change was negative suggesting the possibility of ceiling effect. The table 6 details the goodness-of-fit indexes. Here the researcher found a corrected $\chi^{2}$ value of 92.838 with twenty-four degrees of freedom; the significance value is reported as $p<0.0001$. The researcher found values of 0.022 (CI=0.017-0.026) for RMSE and 0.989 and 0.988 for CFI/TFI respectively. 
Table 6

Selected Results of Growth Curve Model of Mathematics Achievement with Time-Invariant Predictors

\begin{tabular}{ccccccccc}
\hline & \multicolumn{3}{c}{ Standardized Estimates } & \multicolumn{3}{c}{ Unstandardized Estimates } \\
\cline { 2 - 9 } & Est. & SE & Z & Sig & Est. & SE & Z & Sig \\
\hline I (Intercept) I & & & & & & & & \\
PIAT97 & 0.83 & 0.08 & 108.52 & 0.00 & 1.00 & 0.00 & 999.00 & 999.00 \\
PIAT98 & 0.88 & 0.01 & 136.39 & 0.00 & 1.00 & 0.00 & 999.00 & 999.00 \\
PIAT99 & 0.89 & 0.01 & 120.53 & 0.00 & 1.00 & 0.00 & 999.00 & 999.00 \\
PIAT00 & 0.98 & 0.02 & 59.44 & 0.00 & 1.00 & 0.00 & 999.00 & 999.00 \\
PIAT01 & 0.93 & 0.01 & 81.73 & 0.00 & 1.00 & 0.00 & 999.00 & 999.00 \\
PIAT02 & 0.95 & 0.01 & 68.01 & 0.00 & 1.00 & 0.00 & 999.00 & 999.00 \\
S (Slope) I & & & & & & & & \\
PIAT97 & 0.00 & 0.00 & 999.00 & 999.00 & 1.00 & 0.00 & 999.00 & 999.00 \\
PIAT98 & 0.03 & 0.02 & 13.76 & 0.00 & 0.47 & 0.00 & 999.00 & 999.00 \\
PIAT99 & 0.09 & 0.01 & 13.82 & 0.00 & 1.61 & 0.00 & 999.00 & 999.00 \\
PIAT00 & 0.42 & 0.03 & 13.37 & 0.00 & 6.72 & 0.00 & 999.00 & 999.00 \\
PIAT01 & 0.26 & 0.02 & 13.80 & 0.00 & 4.35 & 0.00 & 999.00 & 999.00 \\
PIAT02 & 0.26 & 0.02 & 13.79 & 0.00 & 4.34 & 0.00 & 999.00 & 999.00 \\
Intercept ON & & & & & & & & \\
SDB & 0.05 & 0.02 & 3.471 & 0.00 & 0.99 & 0.29 & 3.47 & 0.001 \\
Gender & -0.02 & 0.02 & -1.048 & 0.29 & -0.51 & 0.49 & -1.05 & 0.295 \\
Slope ON & & & & & & & & \\
SDB & -0.03 & 0.04 & -0.69 & 0.49 & -0.04 & 0.05 & -0.69 & 0.489 \\
Gender & -0.04 & 0.04 & -0.97 & 0.33 & -0.09 & 0.09 & -.098 & 0.329 \\
S with I & & & & & & & & \\
& & & & & & & & \\
\hline
\end{tabular}

Table 7

Selected Goodness-of-fit Statistics for non-linear latent growth curve modeling with

\begin{tabular}{|c|c|c|c|c|}
\hline Test of Model Fit & $\begin{array}{l}\text { Chi-Square Test of Model } \\
\text { Fit }\end{array}$ & CFI/TLI & RMSEA & $\overline{\text { SRMR }}$ \\
\hline Value & 92.838 & $0.989 / 0.988$ & 0.022 & 0.071 \\
\hline Degrees of Freedom & 24 & & & \\
\hline$p$-Value & 0.0000 & & & \\
\hline $\begin{array}{l}90 \text { percent confidence } \\
\text { interval }(\mathrm{CI})\end{array}$ & & & $0.017 / 0.026$ & \\
\hline Probability RMSEA<=.05 & & & 1.000 & \\
\hline
\end{tabular}

The values and estimations based on the fit indexes show that there was a perfect fit in our model. Based on the parameter estimates, aforementioned, the results indicated a non-significant difference in favor of boys for mathematics achievement (Intercept $=-0,02, p=0.295$; Slope $=-0.04, p=0.329$ ). For SDB, students with disruptive behaviors were more successful in mathematics than their peers at the beginning. On the other hand, the slope indicates that students with disruptive behaviors were less successful than their peers. However, the effects of SDB balance out at later grades and there was non-significant slope effect on mathematics trajectories (Intercept $=0.99, p<0.000$; Slope $=-0.03, p=0.489$ ). In the interest of parsimony and nonsignificant time-invariant predictor effects, the researcher specified following covariances were deleted: (a) the slope and intercept for gender and (b) the slope for SDB. The direct effect was neither statistically $(\beta=1.35, p=.46)$ nor practically $\left(R^{2}<.01\right)$ significant. In addition, the 
structural path leading from slope $(\beta=0.003, p=0.069)$ and intercept $(\beta=0.002, p \leq 0.568)$ to outcome variables positive estimate; however they were not significant.

\subsection{Growth Curve Model of Mathematics Achievement with Time-variant Covariate (Parental Earned Income)}

Table 8 and 9 present the results of the linear growth curve model with parental earned income as time-invariant predictor of initial status and growth rate. A path diagram of this model is shown in Figure 4. The results indicated that there was not any significant parental income effect on mathematics achievement trajectories.

The result indicated that the average mathematics achievement score is 102.13 and increases an average of 0.518 points a year. The correlation between the initial status and rate of change was negative suggesting the possibility of ceiling effect. Table 10 details the goodness-of-fit indexes. Here the researcher found a corrected $\chi^{2}$ value of 79.581 with fifty two degrees of freedom; the significance value is reported as $p<0.0001$. The study findings showed values of 0.044 $(\mathrm{CI}=0.023-0.063)$ for RMSE and 0.859 and 0.845 for CFI/TFI respectively. The values and estimations based on the fit indexes show that there was not adequate fit model.

Figure 4

Linear Growth Curve Model of Mathematics Achievement with Time-variant Predictor

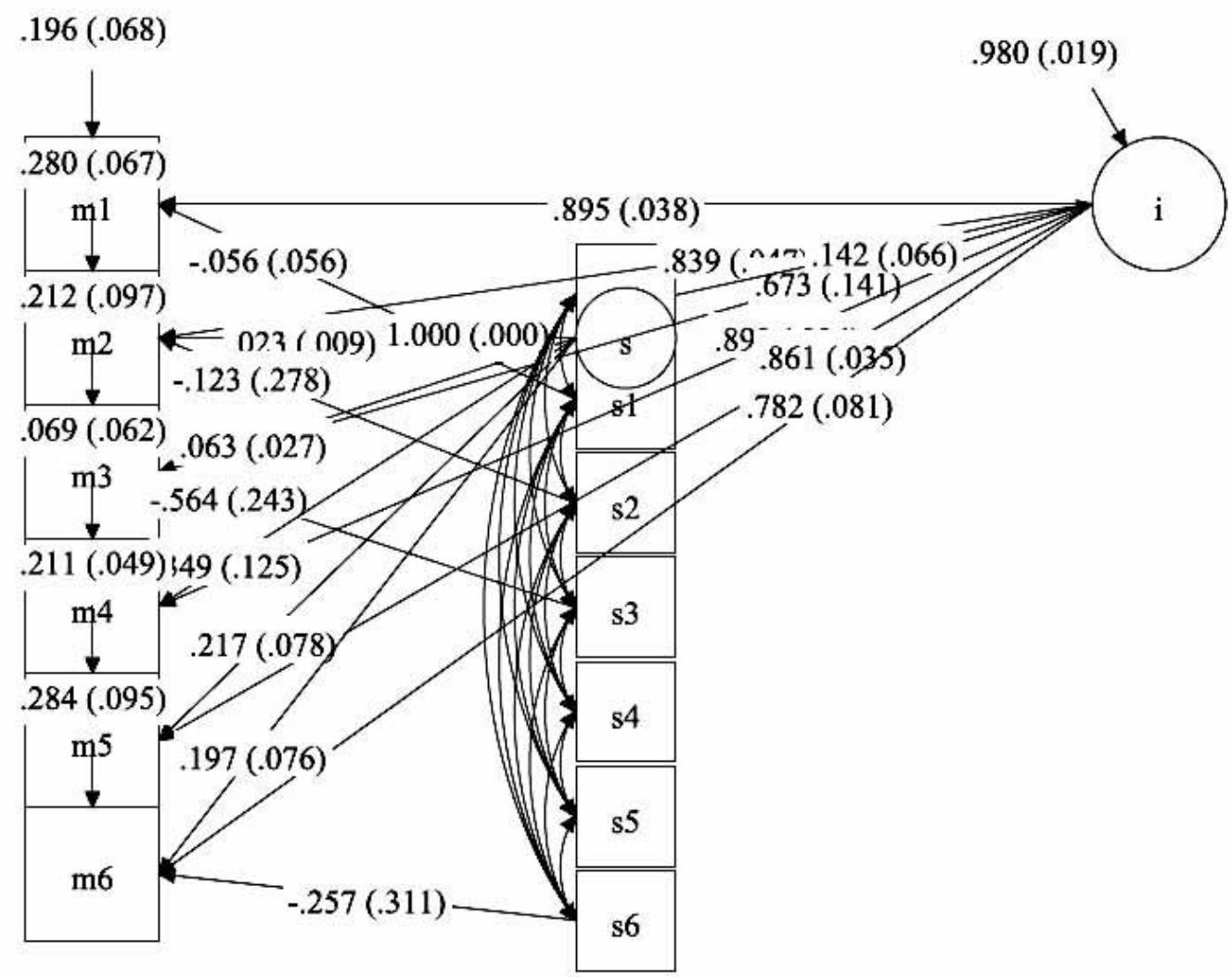

\subsection{Final Latent Growth Curve of Mathematics Achievement}

In the interest of parsimony and non-significant time-invariant and time-variant predictor effects, the researcher specified following covariance were deleted: (a) the slope and intercept for gender; (b) the slope for SDB; (c) the slope and the intercept for Parental Income; (d) also specified I with S to control error variance.

Table 10 and 11 present the results of the linear growth curve model without any covariates of initial status and growth rate. A path diagram of this model is shown in Figure 5. The result 
Table 8

Selected Results of Growth Curve Model of Mathematics Achievement with Time-variant Predictor

\begin{tabular}{ccccccccc}
\hline & \multicolumn{3}{c}{ Standardized Estimates } & \multicolumn{3}{c}{ Unstandardized Estimates } \\
\cline { 2 - 8 } & Est. & SE & Z & Sig & Est. & SE & Z & Sig \\
\hline I (Intercept) I & & & & & & & & \\
PIAT97 & 0.89 & 0.04 & 23.46 & 0.00 & 1.00 & 0.00 & 999.00 & 999.00 \\
PIAT98 & 0.84 & 0.05 & 18.02 & 0.00 & 1.00 & 0.00 & 999.00 & 999.00 \\
PIAT99 & 0.67 & 0.14 & 4.754 & 0.00 & 1.00 & 0.00 & 999.00 & 999.00 \\
PIAT00 & 0.89 & 0.03 & 25.44 & 0.00 & 1.00 & 0.00 & 999.00 & 999.00 \\
PIAT01 & 0.86 & 0.03 & 24.73 & 0.00 & 1.00 & 0.00 & 999.00 & 999.00 \\
PIAT02 & 0.78 & 0.08 & 9.61 & 0.00 & 1.00 & 0.00 & 999.00 & 999.00 \\
S (Slope) I & & & & & & & & \\
PIAT97 & 0.00 & 0.00 & 999.00 & 999.00 & 1.00 & 0.00 & 999.00 & 999.00 \\
PIAT98 & 0.02 & 0.01 & 2.49 & 0.01 & 0.47 & 0.00 & 999.00 & 999.00 \\
PIAT99 & 0.06 & 0.03 & 2.30 & 0.02 & 1.61 & 0.00 & 999.00 & 999.00 \\
PIAT00 & 0.35 & 0.13 & 2.78 & 0.01 & 6.72 & 0.00 & 999.00 & 999.00 \\
PIAT01 & 0.22 & 0.08 & 2.77 & 0.01 & 4.35 & 0.00 & 999.00 & 999.00 \\
PIAT02 & 0.20 & 0.08 & 2.61 & 0.01 & 4.34 & 0.00 & 999.00 & 999.00 \\
Intercept ON & & & & & & & & \\
SDB & 0.142 & 0.066 & 2.146 & 0.03 & 2.23 & 1.05 & 2.13 & 0.03 \\
Income97 & -0.06 & 0.06 & -0.99 & 0.32 & -0.001 & 0.00 & -0.98 & 0.33 \\
Income98 & -0.13 & 0.28 & -0.44 & 0.66 & -0.001 & 0.00 & -0.44 & 0.66 \\
Income99 & -0.56 & 0.24 & -2.33 & 0.20 & 0.001 & 0.00 & -0.16 & 0.12 \\
Income00 & -0.09 & 0.13 & -0.74 & 0.45 & 0.001 & 0.00 & -0.73 & 0.46 \\
Income01 & -0.02 & 0.14 & -0.15 & 0.88 & 0.001 & 0.00 & -0.15 & 0.88 \\
Income02 & -0.26 & 0.31 & -0.83 & 0.41 & -0.001 & 0.00 & -0.77 & 0.44 \\
Slope ON & & & & & & & & \\
SDB & -0.26 & 0.31 & -0.83 & 0.41 & -0.04 & 0.05 & -0.69 & 0.489 \\
\hline
\end{tabular}

Table 9

Selected Goodness-of-fit Statistics for non-linear latent growth curve modeling with Time-Variant Predictor

\begin{tabular}{|c|c|c|c|c|}
\hline Test of Model Fit & $\begin{array}{l}\text { Chi-Square Test of Model } \\
\text { Fit }\end{array}$ & CFI/TLI & RMSEA & SRMR \\
\hline Value & 79.581 & $0.859 / 0.845$ & 0.044 & 0.068 \\
\hline Degrees of Freedom & 52 & & & \\
\hline$p$-Value & 0.0000 & & & \\
\hline $\begin{array}{l}90 \text { percent confidence } \\
\text { interval }(\mathrm{CI})\end{array}$ & & & $0.023 / 0.063$ & \\
\hline Probability RMSEA<=.05 & & & 1.000 & \\
\hline
\end{tabular}

indicated that the average mathematics achievement score is 94.03 and decreases an average of 1.034 points a year. The correlation between the initial status and rate of change was negative suggesting the possibility of ceiling effect. The table 12 details the goodness-of-fit indexes. Here the researcher found a corrected $\chi^{2}$ value of 80.991 with twenty one degrees of freedom; the significance value was reported as $p<0.0001$. Findings revelaed values of $0.022(\mathrm{CI}=0.017-0.027)$ for RMSE and 0.990 and 0.990 for CFI/TFI respectively. The values and estimations based on the fit indexes show that there was a perfect fit in our model. The direct effect was neither statistically $(\beta=0.002, p=0.086)$ nor practically $\left(R^{2}<.01\right)$ significant. In addition, Table 12 presents the indicator and latent $R^{2}$ values. 
Figure 5

Final Linear Growth Curve Model of Mathematics Achievement

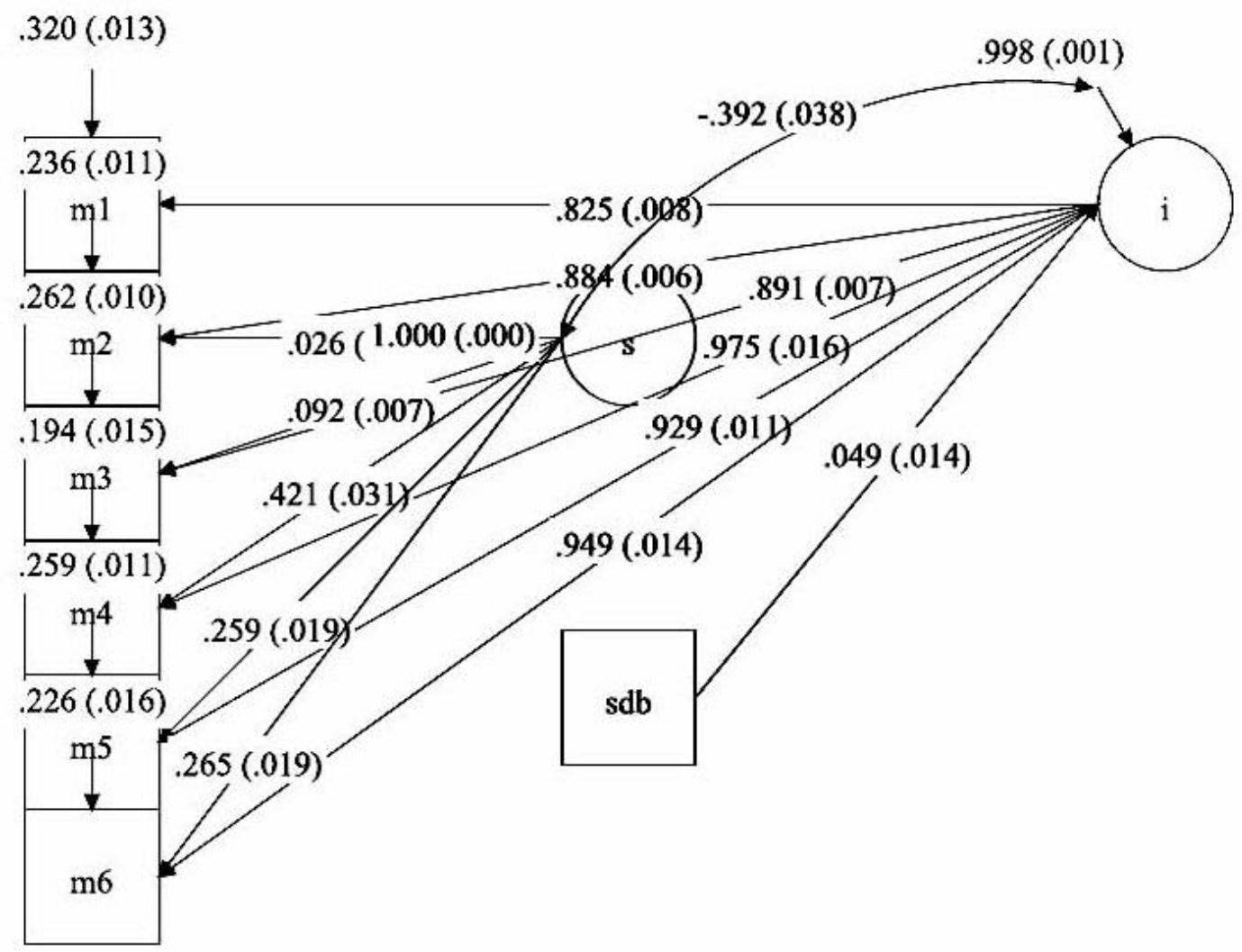

Table 10

Selected Results of Growth Curve Model of Mathematics Achievement

\begin{tabular}{ccccccccc}
\hline & \multicolumn{3}{c}{ Standardized Estimates } & \multicolumn{3}{c}{ Unstandardized Estimates } \\
\cline { 2 - 9 } & Est. & SE & Z & Sig & Est. & SE & Z & Sig \\
\hline I (Intercept) I & & & & & & & & \\
PIAT97 & 0.83 & 0.08 & 108.52 & 0.00 & 1.00 & 0.00 & 999.00 & 999.00 \\
PIAT98 & 0.88 & 0.01 & 136.39 & 0.00 & 1.00 & 0.00 & 999.00 & 999.00 \\
PIAT99 & 0.89 & 0.01 & 120.53 & 0.00 & 1.00 & 0.00 & 999.00 & 999.00 \\
PIAT00 & 0.98 & 0.02 & 59.44 & 0.00 & 1.00 & 0.00 & 999.00 & 999.00 \\
PIAT01 & 0.93 & 0.01 & 81.73 & 0.00 & 1.00 & 0.00 & 999.00 & 999.00 \\
PIAT02 & 0.95 & 0.01 & 68.01 & 0.00 & 1.00 & 0.00 & 999.00 & 999.00 \\
S (Slope) I & & & & & & & & \\
PIAT97 & 0.00 & 0.00 & 999.00 & 999.00 & 1.00 & 0.00 & 999.00 & 999.00 \\
PIAT98 & 0.03 & 0.02 & 13.76 & 0.00 & 0.47 & 0.00 & 999.00 & 999.00 \\
PIAT99 & 0.09 & 0.01 & 13.82 & 0.00 & 1.61 & 0.00 & 999.00 & 999.00 \\
PIAT00 & 0.42 & 0.03 & 13.37 & 0.00 & 6.72 & 0.00 & 999.00 & 999.00 \\
PIAT01 & 0.26 & 0.02 & 13.80 & 0.00 & 4.35 & 0.00 & 999.00 & 999.00 \\
PIAT02 & 0.26 & 0.02 & 13.79 & 0.00 & 4.34 & 0.00 & 999.00 & 999.00 \\
Intercept ON & & & & & & & & \\
SDB & 0.05 & 0.02 & 3.471 & 0.00 & 0.95 & 0.28 & 3.43 & 0.001 \\
S with I & & & & & & & & \\
& -0.40 & 0.04 & -10.47 & 0.00 & -6.675 & 0.84 & -7.98 & 0.000 \\
\hline
\end{tabular}


Table 11

Selected Goodness-of-fit Statistics for latent growth curve modeling

\begin{tabular}{|c|c|c|c|c|}
\hline Test of Model Fit & $\begin{array}{l}\text { Chi-Square Test of Model } \\
\text { Fit }\end{array}$ & CFI/TLI & RMSEA & SRMR \\
\hline Value & 80.991 & $0.990 / 0.990$ & 0.022 & 0.008 \\
\hline Degrees of Freedom & 21 & & & \\
\hline$p$-Value & 0.0000 & & & \\
\hline $\begin{array}{l}90 \text { percent confidence } \\
\text { interval }(\mathrm{CI})\end{array}$ & & & $0.017 / 0.027$ & \\
\hline Probability RMSEA<= $=05$ & & & 1.000 & \\
\hline \multicolumn{5}{|c|}{ Note: RMSEA = Root Mean Square Error of Approximation (RMSEA); SRMR=Standardized Root Mean Square Residual (SRMR). } \\
\hline \multicolumn{5}{|l|}{ Table 12} \\
\hline \multicolumn{5}{|c|}{ Indicator and Latent $R^{2}$ Values } \\
\hline Indicator Variables & Estimate & S.E. & Est. / S.E. & Sig. \\
\hline PIAT97 & 0.680 & 0.059 & 9.612 & 0.000 \\
\hline PIAT98 & 0.764 & 0.057 & 9.788 & 0.000 \\
\hline PIAT99 & 0.730 & 0.057 & 10.278 & 0.000 \\
\hline PIAT00 & 0.806 & 0.065 & 7.646 & 0.000 \\
\hline PIAT01 & 0.741 & 0.054 & 11.705 & 0.000 \\
\hline PIAT02 & 0.774 & 0.053 & 12.173 & 0.000 \\
\hline \multicolumn{5}{|l|}{ Latent Variables } \\
\hline INTERCEPT & 0.002 & 0.001 & 1.710 & 0.086 \\
\hline
\end{tabular}

\section{Discussion and Implications}

The direction of this study changed during the middle of the analyses due to the results of the latent growth modeling and implications from theory; thus, the findings were discussed from the point of view outlined in the modified hypotheses and objectives of the study.

The purpose of this study was to examine the impacts of student gender and classroom disruptive behaviors and parental earned income on students' mathematics achievement trajectories. The hypothesized structure from prior studies would suggest that the gender, student's disruptive behaviors, and parental income would factor as significant predictors for students' mathematics achievement. Fit model without covariates fixed time scores were used to test if the latent growth model was linear. Based on the model results, students' mathematics achievement was not linearly changed during six time points. Therefore, the researcher conducted free time scores to test our model. Then we have added first our time-invariant covariates (i.e., gender and disruptive behaviors). Interestingly, the researcher found that there was not any significant gender effect on students' mathematics achievement trajectories. Specifically, female students were less successful than male students at the beginning; however the results indicate that there was not a significant difference between female and male students in mathematics achievement trajectories. For student disruptive behaviors, students with disruptive behaviors were more successful than their peers with less disruptive behaviors. However, during six time points, there was not any statistically significant difference in the favor of students with disruptive behaviors. Interestingly, contrary to previous studies (e.g., Birch \& Ladd, 1998; Campbell, 1994; Hamre \& Pianta, 2001;Pianta, 1999), students with more aggressive and disruptive classroom behaviors were more successful in mathematics achievement. In fact, it is important to examine gender differences in mathematics self-concept in order to understand the achievement gap in mathematics. Negative gender stereotypes may be an explanation for differences in mathematics success. Namely, gender stereotypes might lead to female students show low interests in mathematics (Lee \& Kung, 2018). Scwart and Siniscrope (2013) argue that gender bias might make 
teachers to exhibit positive attitudes towards mathematics in male students and negative attitudes in their female peers. In this sense, İlhan et al. (2021) found that mathematics achievement was positively predicted by mathematical attitudes and problem-solving skills.

After adding time-variant covariate (earned income), the latent growth curve model parameter estimates indicated there was not any significant parental earned income impact on students' mathematics achievement. Although the average mathematics achievement score was 102.13 and increases an average of 0.518 points a year, this positive growth rate trend was not statistically significant as compared to previous studies (e.g., Catsambis, 1994; Fennema \& Shearmen, 1977).

For the final model, the researcher examined the final model without any time-covariate and time-incovariate variables; however the researcher specified the significant intercept effect of student disruptive behavior and the correlation between the slope and the intercept to decrease the residual variances to increase the model fit indexes. As expected, the final growth curve model was perfect with these modifications. In addition, the researcher could not compute the r-square for each predictor because of non-significant effects of all predictors.

\section{Limitations}

Although, this analysis provided initial evidence on the effects of the student gender, disruptive behavior, and parental income, a few limitations require discussion. These limitations were found in the nature of longitudinal sample, the administration of the items, and during analysis of longitudinal data. The following paragraphs will detail these limitations and their impact on the study threats to validity.

\subsection{Internal Validity}

Internal validity refers to the extent that the covariation between the independent variable and the dependent variable was the result of a causal relationship (Shadish, 2002). The causal links that have been established in this study were not without some error. The degree of control exerted over potential extraneous variables determines the level of internal validity. In addition, controlling for potentially confounding variables minimizes the potential for an alternative explanation for treatment effects and provides more confidence that effects are due to the independent variable. Because the sample was based on longitudinal data, there was much data missing that could have helped to explain the changes in the reports on mathematic achievement trajectories. The non-linear and non-significant predictor impacts could be accounted for by the data missingness. History might be a threat when other academic (e.g., tutoring) and nonacademic factors (e.g., teacher-student relationship), external factors to the subject occur by the virtue of passage of time. For the maturation, this threat can operate when biological or psychological changes occur within subjects and these changes may account in part for the mathematics achievement trajectories because the data is based on the six time points. In addition, when study results might be due to changes in instrument calibration or observer changes rather than to a true treatment effect, the instrumentation threat is in operation. For example, specifically for student disruptive behavior, teachers reported their perception about their students' observed classroom behaviors and the student might have different teachers along their educational life. Besides these internal validity threats, we did not believe that there were not differential selection, experimental mortality, and selection interactions. Because of these aforementioned factors, we lose some confidence in claiming causality, but revert to theory as a way to substantiate that loss.

\subsection{External Validity}

External validity is the value of the knowledge claim and its generalizability to a variety of persons, treatments, observations, and settings (Shadish, 2002). Because of the nature of the longitudinal data and the limitations of available participants, the data were not collected by random sampling. In addition, although about 9000 people aged 12-16 years old included in this study, a wide range of participants were from only Hispanic and African-American racial groups. This should not reflect the real distribution of the US ethnic population, creating a situation in 
which a limited sample size was the basis upon which all analyses were founded. These characteristics limit the confidence that we have in claiming these findings on other individuals across the US population.

\subsection{Statistical Conclusion Validity}

Statistical conclusion validity refers to the extent that the independent variable and the dependent variable actually covary and that the effect of said covariance is significant (Shadish, 2002). Limitations in studies that focus on this tend to be related to the statistical characteristics such as low power, unreliable measures, data fishing, extraneous variance, etc. In this study, the effects that the student gender, parental earned income, and student disruptive behavior had significant effects on students' mathematics achievement trajectories, while non-significant, and very low. The low and non-significant effects need to be approached with caution and reevaluated to determine that a Type 2 error was not made in regards to the declaration that it was not statistically significant; when in other circumstances might be based on previous researches.

\subsection{Construct Validity}

Construct validity is the claim that what is being measured is representative of the higher order constructs that are being inferred (and vice versa) (Shadish, 2002). The researcher did believe that especially for the construct of student disruptive behavior was not well-established because the construct of student disruptive behavior should not be based on only one item score. In addition, the current study used the NLSY97 longitudinal data and their measures; however they did not provide clear explanation regarding the construct validity of their measure of student disruptive behaviors.

\section{Directions for Future Research}

Future research on students' mathematical achievement trajectories should look into the role that other significant psychological (e.g., self-efficacy belief) and background (e.g., ethnicity) and relational (e.g., teacher-student relationship) constructs play in their mathematics achievement. From this study, the researcher was able to examine the role of student gender, their disruptive behaviors, and parental earned income on mathematics achievement trajectories. However, we could not find any significant effects of any predictors on math achievement in six time points. In addition, the explained variance in these constructs is fairly low. Exploring the role of aforementioned factors would offer a greater explanation in students' mathematics achievement. Future research on students' mathematics achievement trajectories should also look into the role of student gender, parental income, and student disruptive behavior with different sample to confirm or disconfirm the findings of the study.

\section{Conclusion}

In conclusion, problem solving world, mathematical skills and ability are crucial for future generations' successes. Therefore, it is critical for us to document and understand the impacts of psychological, relational, and demographic factors on students' mathematics achievement trajectories. The findings of the current study will help the researchers to shed light on the predictive role of students' gender, parental income, and disruptive classroom behaviors; however, there is still a need to reexamine the effects of these factors on mathematics achievement because of intricate study results. 


\section{References}

Achenbach, T. M. (1991). Manual for the youth self-report and 1991 profile. University of Vermont Department of Psychiatry.

Beilock, S. L., Gunderson, E. A., Ramirez, G., \& Levine, S. C. (2010). Female teachers' math anxiety affects girls' math achievement. Proceedings of the National Academy of Sciences, 107(5), 1860-1863. https://doi.org/10.1073/pnas.0910967107

Birch, S. H., \& Ladd, G. W. (1998). Children's interpersonal behaviors and the teacher-child relationship. Developmental Psychology, 34(5), 934-946.

Blackwell, L. S., Trzesniewski, K. H., \& Dweck, C. S. (2007). Implicit theories of intelligence predict achievement across an adolescent transition: A longitudinal study and an intervention. Child Development, 78(1), 246-263. https:// doi.org/10.1111/j.1467-8624.2007.00995.x

Blank, R., \& Langesen, D. (1999).State indicators of science and mathematics education. Council of Chief State School Officers.

Blums, A., Belsky, J., Grimm, K., \& Chen, Z. (2016). Building links between early socioeconomic status, cognitive ability, and math and science achievement. Journal of Cognition and Development, 18(1), 1-25. https:// doi.org/10.1080/15248372.2016.1228652

Burrill, G. (1998). Changes in your classroom: From the past to the present to the future. Journal for Research in Mathematics Education, 29(5), 583-596.

Campbell, S. B. (1994). Hard-to-manage preschool boys: Externalizing behavior, social competence, and family context at two-year followup. Journal of Abnormal Child Psychology,22(2), 147-166. https://doi.org/10.1007/BF02167897

Casey-Cannon, S., Hayward, C., \& Gowen, K. (2001). Middle-school girls' reports of peer victimization: Concerns, consequences, and implications. Professional School Counseling, 5(2), 138-147.

Catsambis, S.( 1994). The path to math: Gender and racial-ethnic differences in mathematics participation from middle school to high school. Sociology of Education, 56, 13-21.

Cvencek, D., Meltzoff, A. N., \& Greenwald, A. G. (2011). Math-gender stereotypes in elementary school children. Child Development, 82(3), 766-779. https:// doi.org/10.1111/j.1467-8624.2010.01529.x

DiPrete, T. A., \& Jennings, J. L. (2012). Social and behavioral skills and the gender gap in early educational achievement. Social Science Research, 41(1), 1-15. https:/ / doi.org/10.1016/j.ssresearch.2011.09.001

Evans, W.N., Shelia E. M., \& Robert M. S. (1997). Schoolhouses, courthouses, and statehouses after Serrano. Journal of Policy Analysis and Management, 16, 10-31. https://doi.org/10.1002/(SICI)15206688(199724)16:1\%3C10::AID-PAM2\%3E3.0.CO;2-L

Fennema, E. \& J. Sherman (1977). Sex related differences in mathematics achievement, spatial visualization and affective factors. American Educational Research Journal, 14, 51-71. https://doi.org/10.3102/00028312014001051

Flora-Mendoza, C., Widaman, K., Mansur-Alves, M., Bacelar, T. D., \& Saldanha, R. (2013). Psychoticism and disruptive behavior can be also good predictors of school achievement. The Spanish Journal of Psychology, 16, E13. https://doi.org/10.1017/sjp.2013.3

Goldman, A. D., \& Penner, A. M. (2014). Exploring international gender differences in mathematics selfconcept. International Journal of Adolescence and Youth, 21(4), 403-418. https://doi.org/10.1080/02673843.2013.847850

Good, C., Rattan, A., \& Dweck, C. S. (2012). Why do women opt out? Sense of belonging and women's representation in mathematics. Journal of Personality and Social Psychology, 102(4), 700-717. https://doi.org/10.1037/a0026659

Hamre, B. K., \& Pianta, R. C. (2001). Early teacher-child relationships and the trajectory of children's school outcomes through eighth grade. Child Development, 72(2), 625-638. https://doi.org/10.1111/14678624.00301

İlhan, A., Gemcioğlu, M., \& Poçan, S. ( 2021). The relationship between secondary school students' mathematical attitudes and perceptions towards problem solving and mathematical achievement. MSKU Ĕ̆itim Fakültesi Dergisi, 8(1), 1-15.

Jain, S., \& Dowson, M. (2009). Mathematics anxiety as a function of multidimensional self-regulated and self$\begin{array}{lllll}\text { efficacy. } & \text { Contemporary } & \text { Educational } & \text { 240-249. }\end{array}$ https:// doi.org/10.1016/j.cedpsych.2009.05.004

Jansen, B. R. J., Louwerse, J., Straatemeier, M., Van der Ven, S. H. G., Klinkenberg, S., \& Van der Maas, H. L. J. (2013). The influence of experiencing success in math on math anxiety, perceived math competence, and 
math performance. Learning and Individidual Differences, 24, 190-197. https://doi.org/10.1016/j.lindif.2012.12.014

Lee, C-Y. \& Kung, H-Y.(2018). Math self-concept and mathematics achievement: Examining gender variation and reciprocal relations among junior high school students in Taiwan. EURASIA Journal of Mathematics, Sciences and Technology Education, 14(4), 1239-1252. https:// doi.org/10.29333/ejmste/82535

Louis, R. A., \& Mistele, J. M. (2012). The differences in scores and self-efficacy by student gender in mathematics and science. International Journal of Science and Mathematics Education, 10(5), 1163-1190. https:// doi.org/10.1007/s10763-011-9325-9

Merikangas, K. R., Nakamura, E. F., \& Kessler, R. C. (2009). Epidemiology of mental disorders in children and adolescents. Dialogues in Clinical Neuroscience, 11(1), https:/ / dx.doi.org/10.31887/DCNS.2009.11.1/krmerikangas

Nagy, G., Watt, H. M., Eccles, J. S., Trautwein, U., Lüdtke, O., \& Baumert, J. (2010). The development of students' mathematics self-concept in relation to gender: Different countries, different trajectories?. Journal of Research on Adolescence, 20(2), 482-506. https://doi.org/10.1111/j.15327795.2010.00644.x

Namkung, J. M., Peng, P., and Lin, X. (2019). The relation between mathematics anxiety and mathematics performance among school-aged students: a meta-analysis. Review of Educational Research, 89, 459-496. https:// doi.org/10.3102/0034654319843494

Niepel, C., Stadler, M., \& Greiff, S. (2019). Seeing is believing: Gender diversity in STEM is related to mathematics self-concept. Journal of Educational Psychology, 111(6), 1119-1130. https://psycnet.apa.org/doi/10.1037/edu0000340

Nosek, B. A., Smyth, F. L., Sriram, N., Lindner, N. M., Devos, T., Ayala, A., \& Kesebir, S. (2009). National differences in gender-science stereotypes predict national sex differences in science and math achievement. Proceedings of the National Academy of Sciences, 106(26), 10593-10597. https://doi.org/10.1073/pnas.0809921106

Ozogul, G., \& Sullivan, H. (2009). Student performance and attitudes under formative evaluation by teacher, self and peer evaluators. Educational Technology Research and Development, 57(3), 393-410. https:// doi.org/10.1007/s11423-007-9052-7

Pianta, R. C. (1999). Enhancing relationships between children and teachers. American Psychological Association.

Ross, S. W., Romer, N., \& Horner, R. H. (2012). Teacher well-being and the implementation of school-wide positive behavior interventions and supports. Journal of Positive Behavior Interventions, 14(2), 118-128. https:// doi.org/10.1177/1098300711413820

Rubie-Davies, C. M., \& Lee, K. (2013). Self-concept of students in higher education: are there differences by faculty and gender? Educational Studies, 39(1), 56-67. https://doi.org/10.1080/03055698.2012.671513

Schwartz, C.S. and Sinicrope, R. (2013). Prospective elementary teachers' perceptions of gender differences in children's attitudes toward mathematics. School Science and Mathematics, 113(8), 410-416. https://doi.org/10.1111/ssm.12045

Shadish, W. R. (2002). Revisiting field experimentation: field notes for the future. Psychological Methods, 7(1), 3-18. https:// doi.org/10.1037/1082-989X.7.1.3

Spelke, E. (2005). Sex differences in intrinsic aptitude for mathematics and science? A critical review. American Psychologist Journal, 60, 950-958. https://doi.org/10.1037/0003-066X.60.9.950

Suldo, S., Thalji, A., \& Ferron, J. (2011). Longitudinal academic outcomes predicted by early adolescents' subjective well-being, psychopathology, and mental health status yielded from a dual factor model. The Journal of Positive Psychology, 6, 17-30. https:/ / doi.org/10.1080/17439760.2010.536774

Williams, K. E., White, S. L. J., and MacDonald, A. (2016). Early mathematics achievement of boys and girls: do differences in early self-regulation pathways explain later achievement? Learning and Individual Differerences, 51, 199-209. https:// doi.oeg/10.1016/j.lindif.2016.09.006

Zimmermann, F., Schütte, K., Taskinen, P., \& Köller, O. (2013). Reciprocal effects between adolescent externalizing problems and measures of achievement. Journal of Educational Psychology, 105(3), 747-761. https://doi.org/10.1037/a0032793 